\title{
Preliminary observations on the use of low temperatures in the cultural heritage protection
}

\begin{abstract}
Each insect species has different temperature optima: the more this parameter deviates from these values the more the insect suffers negative consequences, up to the death. Temperature can be easily editable. Therefore, the application of low temperatures may represent a physical method for the protection of valuable cultural objects, alternative, for example, to chemical ones.

In this paper we report laboratory tests results, carried out on Trogoderma inclusum LeConte (Coleoptera: Dermestidae), a species harmful to leather items such as bindings of books and mummies, in order to reach its control by applying low temperatures. The tests were conducted using specimens obtained from laboratorybreeding blocks maintained at $27 \pm 2{ }^{\circ} \mathrm{C}$ and $75 \pm 5 \%$ R.H., in a temperaturecontrolled room of the Institute of Entomology and Plant Pathology, Piacenza. The aim of the tests was to determine the time necessary to obtain the total mortality of the different instars of development at temperatures of $-10^{\circ} \mathrm{C}$ and $-20^{\circ} \mathrm{C}$. The insects, in the various instars of development of egg, larva, pupa and adult, were treated with low temperatures in two different ways:

- inserting the Petri dishes containing the insects directly in the freezer without any protection, in order to obtain an immediate lowering of the temperature, and - inserting the Petri dish in a niche carved in an old book so that the lowering of the temperature is gradual. In some cases the insects were kept at $+4^{\circ} \mathrm{C}$ for a time before the test to determine whether exposure to low temperature before treatment could induce a resistance to it.

The results show that the method can be validly applied for cultural heritage objects protection, attacked by the species concerned.
\end{abstract}

Key words: low temperature, freezing, insect, cultural heritage.

\section{INTRODUCTION}

Low temperatures for cultural properties protection were first utilized in the 1980ies. Brokerhof (1993) cites authors who demonstrated low temperatures efficacy for museum objects disinfestation of library materials.

Very important conservation structures (e.g. British Museum, Horniman Museum in London, Birmingham Museum and Art Gallery), possess specific facilities for low temperature treatments that are often used in case of the arrival of new collections so as 
to avoid pest introduction (Pinniger, 2010). Entomological collection are also periodically treated with low temperature.

But what about the effects that freeze can have on different materials? Limited information is available. Only some substrates have been tested so that it can be difficult to extrapolate from results obtained with paper, wool, cotton, linen, general rules valid for all the other materials that make-up cultural properties (Koestler et al., 2004).

Generally, low temperature is not advisable for canvas and wood-panel paintings, painted or inlaid wooden objects, finished furniture, lacquered wooden objects, objects under tension (e.g. drums, strung parchments), composite objects containing ivory or teeth and inorganic materials, such as glass, high-fired ceramics, metal (State Library of Queensland report, 2008 - Integrated Pest Management Working Group, Treatment Subgroup, report 2008).

On the whole objects which are very poor in water content are those less affected by the treatment as, for example, textiles, leather, very dry wood and paper, entomological collections, herbaria. The majority of organic materials conserved as cultural heritage contains some water (8-12\%) but this should be "bound" and therefore unavailable for the formation of ice crystals (Koestler et al., 2004).

Notwithstanding the positive interest in this technique, at present still few scientific data, which confirm its efficacy, are available as well as data on different treatment times or application temperatures. Strang (1992) reports a considerable number of bibliographical data on the use of cold in the cultural heritage. To obtain $100 \%$ mortality it is expected to reach quite low temperatures $\left(-40^{\circ} \mathrm{C},-25^{\circ} \mathrm{C},-20^{\circ} \mathrm{C}\right)$, and keep them for at least a week (Strang, 1997) but it should be very important to know also other different mortality conditions in order to dispose of a more plastic method that could be adapted to different situation.

There are many studies on behaviour and physiology of insects in cold conditions. Insects defend themselves from low temperatures adopting typical actions such as migration to warmer regions or moving to protected sites or to sometimes very complicated metabolic mechanisms (Danks, 2007). Cold hardiness is a dynamic condition that varies greatly from one species to another, and even from one instar to another that results from a complex of strategies often strongly linked to each other and not always completely known (Clark \& Worland, 2008),

Considering metabolic cold hardiness, insects able to survive at low temperatures can be divided into three categories:

- insects that can tolerate freezing, surviving the ice formation inside their tissues (freeze tolerance),

- insects that are able to avoid freezing, keeping fluids in their body below the melting point (freeze avoidance) (Bale, 2002; Sinclair et al., 2003), and

- insects that decrease the melting point so keeping the fluids in equilibrium with the steam pressure of the surrounding ice (cryoprotective dehydration) (Sinclair et al., 2003).

Insects living in continental climate are equipped to bypass the winter period adopting these strategies through many different metabolic mechanisms, reviewed by 
Bale (2002), Danks (2007) and Clark \& Worland (2008), that are triggered by a gradual lowering of temperatures in the fall.

On the opposite, in the case of a sudden and significant drop in temperature, insects often have few instruments to oppose. Nevertheless, if the sudden exposure to low temperatures is preceded by an exposure, even for short periods, at less rigid temperatures (rapid cold hardening), the effects are not so serious. Lee et al. (1987) demonstrated that in some species the survival after an exposure of two hours at $-10^{\circ} \mathrm{C}$, usually of $5-30 \%$, increases by about $90 \%$ after two hours of pre-exposure at $0^{\circ} \mathrm{C}$. The rapid cold hardening $(\mathrm{RCH})$ response could also be caused by other stresses, including anoxia and thermal shock from high temperatures, suggesting that it is probably part of a general insect response to stress (Sinclair et al., 2003).

It is therefore obvious (but not very often considered) that it is basic, for the applicability of the method, to know also the influence of aspects other than time and temperature i.e. how sudden is the temperature drop, temperature level prior to the treatment, the effects of possible variation in treatment temperature, etc.

In addition, if we consider Strang (1997) recommendations, it goes without saying that achieving and maintaining very low temperatures for several days with special equipment can be very expensive. So try taking into account higher temperatures and shorter treatment time could, if effective, lower treatment costs and also reduce the risks of damages to the artefacts.

In this study we want to determine the influence of a rapid or gradual drop of temperature for the efficacy of the method considering the aim of obtaining $100 \%$ mortality.

\section{MATERIALS AND METHODS}

The species used for the experiments is Trogoderma inclusum LeConte (Coleoptera: Dermestidae). Laboratory cultures are maintained in aerated containers and fed with dry fish and pollen at $25 \pm 1{ }^{\circ} \mathrm{C}$ and $75 \pm 5 \%$ R.H..

The adults pupae and larvae used were directly taken from the laboratory cultures, while eggs were obtained from adults females which were let to oviposit for 2-3 days in Petri dishes.

In every experiment we used 10 individuals, possibly of each instar, placed in a ventilated box on a mixture of dry fish and pollen. Every experiment considered two replicates.

For the experiments a refrigerator at $+4^{\circ} \mathrm{C}$, a freezer at $-20 \pm 2{ }^{\circ} \mathrm{C}$ (both domestic) and a cold store at $-10^{\circ} \mathrm{C}$ were used.

To evaluate different refrigeration speeds the ventilate box were used without any protection or either introduced in a special niche carved in an old book or in the book and than in a polystyrene container with insulating the chips. To evaluate a possible development of resistance to low temperatures, some of the tests were realized preconditioning the insects for a period of time at $+4^{\circ} \mathrm{C}$ before treatment at temperatures below $0^{\circ} \mathrm{C}$. 
The R.H. and temperature were logged with electronic data loggers placed in the book niche or directly into the freezer.

At the end of the treatment, the ventilated boxes were removed from the freezer and protections and the living and dead individuals were counted.

The ventilated boxes were subsequently maintained in a rearing chamber for one week (a fortnight for eggs) in order to verify eggs hatching, pupae ecdysis and a possible recovery. After that the final mortality percentage was assessed.

In the beginning, longest experimental times were used. In case total mortality was obtained treatment times were progressively shortened. At first preconditioning time lasted 7 days, subsequently we prolonged it to 40 days.

Every experiment considered a test at specific conditions as summarized in Tab. 1 and a control kept at room temperature $\left(21^{\circ} \mathrm{C}\right)$ for the same time of the experiment.

At the end of the treatment, the data logger were removed from freezer and protections and temperature graphics were elaborated, in order to highlight the total time passed at the different temperatures below $0^{\circ} \mathrm{C}$ and the time necessary to reach them.

\begin{tabular}{|c|c|c|c|c|}
\hline Temperature & Conditioning & $\begin{array}{c}\text { Time } \\
\text { (hours) }\end{array}$ & Insects protection & Instars \\
\hline$-22 \pm 2^{\circ} \mathrm{C}$ & no & $24,12,6$ & book + polystyrene & all \\
\hline$-22 \pm 2^{\circ} \mathrm{C}$ & 7 days & $24,12,6$ & book + polystyrene & all \\
\hline$-22 \pm 2^{\circ} \mathrm{C}$ & 40 days & 6 & book + polystyrene & larvae \\
\hline$-22 \pm 2^{\circ} \mathrm{C}$ & no & 6 & book & all \\
\hline$-22 \pm 2^{\circ} \mathrm{C}$ & 7 days & 6 & nothing & all \\
\hline$-22 \pm 2^{\circ} \mathrm{C}$ & no & 5,3 & nothing & all \\
\hline$-22 \pm 2^{\circ} \mathrm{C}$ & 40 days & 3 & nothing & larvae \\
\hline$-10^{\circ} \mathrm{C}$ & no & 5 & nothing & all \\
\hline
\end{tabular}

Tab. 1 - Tests carried out with the related parameters.

\section{RESULTS AND DISCUSSION}

Results are summarized in Tab. 2. Total mortality was obtained in all treatments 24 or 12 hours long. When book and polystyrene protections are present, from 2:00 to $2: 45 \mathrm{~h}$ are necessary to reach $0^{\circ} \mathrm{C}$. From $0^{\circ} \mathrm{C}$ the temperature drops half a degree every 10 minutes and about six hours are needed to reach $-20^{\circ} \mathrm{C}$. Therefore, in $6 \mathrm{~h}$ treatment at $-20^{\circ} \mathrm{C}$, with book and polystyrene protection, the specimens do not have enough time to reach the lowest temperature. In the same conditions, when a 7 days preconditioning period is present, the temperature is already low when the polystyrene box is inserted into the freezer, hence allowing to reach $-20^{\circ} \mathrm{C}$ and keeping it for the minimum time. In this case, a mortality of all instars, although not always complete, was obtained (Tab. 2). 


\begin{tabular}{|c|c|c|c|c|c|c|c|}
\hline Temperature & Conditioning & $\begin{array}{c}\text { Time } \\
\text { (hours) }\end{array}$ & Insects protection & adults & pupae & larvae & eggs \\
\hline$-22 \pm 2^{\circ} \mathrm{C}$ & no & 24 & book + polystyrene & $100 \%$ & $100 \%$ & $100 \%$ & $100 \%$ \\
\hline$-22 \pm 2^{\circ} \mathrm{C}$ & 7 days & 24 & book + polystyrene & $100 \%$ & $100 \%$ & $100 \%$ & $100 \%$ \\
\hline$-22 \pm 2^{\circ} \mathrm{C}$ & no & 12 & book + polystyrene & $100 \%$ & $100 \%$ & $85 \%$ & $100 \%$ \\
\hline$-22 \pm 2^{\circ} \mathrm{C}$ & 7 days & 12 & book + polystyrene & $100 \%$ & $100 \%$ & $100 \%$ & $100 \%$ \\
\hline$-22 \pm 2^{\circ} \mathrm{C}$ & no & 6 & book + polystyrene & $0 \%$ & $100 \%$ & $15 \%$ & $100 \%$ \\
\hline$-22 \pm 2^{\circ} \mathrm{C}$ & 7 days & 6 & book + polystyrene & $63 \%$ & $100 \%$ & $45 \%$ & $100 \%$ \\
\hline$-22 \pm 2^{\circ} \mathrm{C}$ & no & 6 & book & $100 \%$ & $100 \%$ & $100 \%$ & $100 \%$ \\
\hline$-22 \pm 2^{\circ} \mathrm{C}$ & 7 days & 6 & nothing & $100 \%$ & $100 \%$ & $100 \%$ & $100 \%$ \\
\hline$-22 \pm 2^{\circ} \mathrm{C}$ & 40 days & 6 & book + polystyrene & - & - & $85 \%$ & - \\
\hline$-22 \pm 2^{\circ} \mathrm{C}$ & no & 5 & nothing & $100 \%$ & $100 \%$ & $100 \%$ & $100 \%$ \\
\hline$-22 \pm 2^{\circ} \mathrm{C}$ & no & 3 & nothing & $100 \%$ & $100 \%$ & $100 \%$ & $100 \%$ \\
\hline$-22 \pm 2^{\circ} \mathrm{C}$ & 40 days & 3 & nothing & - & - & $90 \%$ & - \\
\hline$-10^{\circ} \mathrm{C}$ & no & 5 & nothing & $95 \%$ & $100 \%$ & $100 \%$ & $100 \%$ \\
\hline
\end{tabular}

Tab. 2 - Tests carried out with the related parameters.

Nevertheless, with minor protection (only the book), total mortality was achieved. In this case, the temperature drop was quicker and the temperature of $-20^{\circ} \mathrm{C}$ was reached about two hours before the experiment ended.

When assessing preconditioning ( 7 days) and treatment without protection, total mortality was obtained, showing that such a preconditioning was ineffective. We therefore tested a longer preconditioning period (40 days) that proved to have some influence as the larvae mortality was reduced.

In five days treatment, obviously without protections, total mortality was achieved.

Three days treatment was again performed only without protections and total mortality was obtained. In this case, with a preconditioning of 40 days, the mortality of the larvae did not reach $100 \%$, thus indicating again a possible development of cold hardiness.

\section{CONCLUSIONS}

Three hours at $-20 \pm 2{ }^{\circ} \mathrm{C}$ are enough to kill all instars of Trogoderma inclusum. The slower decrease of temperature obtained with book and polystyrene protections, seems to have no influence with respect to mortality, if the lowest temperature is reached and maintained for the minimum time. Results are dependent on the time passed at the minimum temperature, notwithstanding the time employed to reach it. 
On the other hand preconditioning at $4^{\circ} \mathrm{C}$ could affect mortality. This is very important considering different conditions of conservations prior to treatment. Sometimes, objects are kept in cellars or in not heated structure and they must be treated before transferring them to other spaces.

Freezing application can also pose some practical limits in relation to the apparatus used for it. If a simple freezer is utilized the objects must be of little or medium size so that they can be inserted into.

Attention must be paid to the materials which compose the objects because they could be damaged both directly by the freeze or by subsequent condensation.

In order to avoid the problem of condensation the State Library of Queensland, Report, 2008, recommends to place the objects to be treated inside cellophane vacuum bags.

\section{REFERENCES}

BALE J.S., 2002 - Insects and low temperatures: from molecular biology to distributions and abundance. Phil. Trans. R. Soc. Lond., B 357: 849-862.

Brokerhof A.W., Morton R., Banks H.J., 1993 - Time - mortality relationships for different species and developmental stages of clothes moths (Lepidoptera: Tineidae) exposed to cold. K. stored Prod. Res., 29 (3): 277-282.

Clark M.S., Worland M.R., 2008 - How insects survive the cold: molecular mechanisms a review. J. Comp. Physiol., B (178): 917-933.

DANKs H.V., 2007 - The elements of seasonal adaptations in insects. Can. Entomol., 139: 1-44. Integrated Pest Management Working Group, Treatment Subgroup, report 2008 - Pest Treatment Case Study: Low temperature pest management treatment at the Smithsonian National Museum of the American Indian. www.museumpests.net

Koestler R.J., Tavzes C., Pohleven F., 2004 - A new approach on conservation of wooden heritage. The international research group on wood preservation. $35^{\text {th }}$ Annual Meeting - Ljubljana, Slovenia, 6-10 June 2004.

Lee R. E., Chen C., Denlinger D. L., 1987 - A rapid cold-hardening process in insects. Science, New Series, 238 (4832): 1415-1417.

PinNigER D.B., 2010 - Saving our heritage. Pest management in museums and historic houses. Outlooks on Pest Management, October 2010.

Sinclair B.J., Vernon P., Jaco KloK C., Chown S.L., 2003 - Insects at low temperatures: an ecological perspective. Trends in Ecology and Evolution, 18 (5): 257-262.

State Library of Queensland, report, 2008 - Caring for your collections: pest management- freezing. www.slq.qld.gov.au

StRANG J.K., 1992 - A review of published temperatures for the control of pest insects in museums. Collection Forum, 8(2): 41-67.

StRANG J.K., 1997 - Controlling insect pests with low temperature. Canadian Conservation Institute Notes, 3/3, 1-4.

Maria Cristina Reguzzi, Istituto di Entomologia e Patologia vegetale, Facoltà di Agraria, Università Cattolica del Sacro Cuore, via Emilia Parmense 84, I-29122 Piacenza, Italy.

E-mail: cristina.reguzzi@gmail.com 